\title{
Endoscopic retrograde transabdominal ultrasound-guided bile duct drainage during COVID-19 pandemic
}

Suppurative cholangitis is a life-threatening condition requiring urgent decompression of the biliary tree [1]. Currently, endoscopic retrograde cholangiopancreatography (ERCP) is the standard method to drain the bile ducts. Herein, we present a novel method of radiationfree, direct endoscopic drainage of the common bile duct using transabdominal ultrasound.

A 78-year-old woman with a history of hypertension, coronary artery disease, atrial fibrillation, and diabetes mellitus type II, and status post-cholecystectomy 20 years prior, presented with epigastric abdominal pain, fever, chills, and jaundice. On clinical examination she appeared ill and her blood pressure was 90/ $50 \mathrm{mmHg}$ with pulse of $100 \mathrm{bpm}$. Laboratory data showed a white blood cell count of $20.03 \mathrm{Gpt} / \mathrm{L}$ (normal range 410), elevated liver tests, and cholestatic parameters. Glutamic oxaloacetic transaminase was $226 \mathrm{U} / \mathrm{L}(<42)$, glutamic pyruvic transaminase was $135 \mathrm{U} / \mathrm{L}(<40)$, alkaline phosphatase was $635 \mathrm{U} / \mathrm{L}(<78)$, international normalized ratio was 3.6 , C-reactive protein was $314.3 \mathrm{mg} / \mathrm{L}$ $(<5 \mathrm{mg} / \mathrm{L})$. On transabdominal ultrasound, a large amount of sludge was observed in a massively dilated common bile duct ( $\triangleright$ Fig. 1 ). The intrahepatic bile ducts were also dilated ( $\triangleright$ Video 1 ). The patient was admitted to the intermediate care unit and aggressive fluid resuscitation, intravenous vitamin $\mathrm{K}$, and broadspectrum intravenous antibiotics (piperacillin/tazobactam) were administered. A diagnosis of bile stone-induced severe cholangitis (Tokyo criteria III) was made and a decision to perform an urgent ERCP was taken. Unfortunately, the Carm broke and no possibilities to use other X-ray equipment existed. As this admission occurred during the COVID-19 pandemic, it was impossible to transfer the patient to another hospital. The patient provided informed consent to

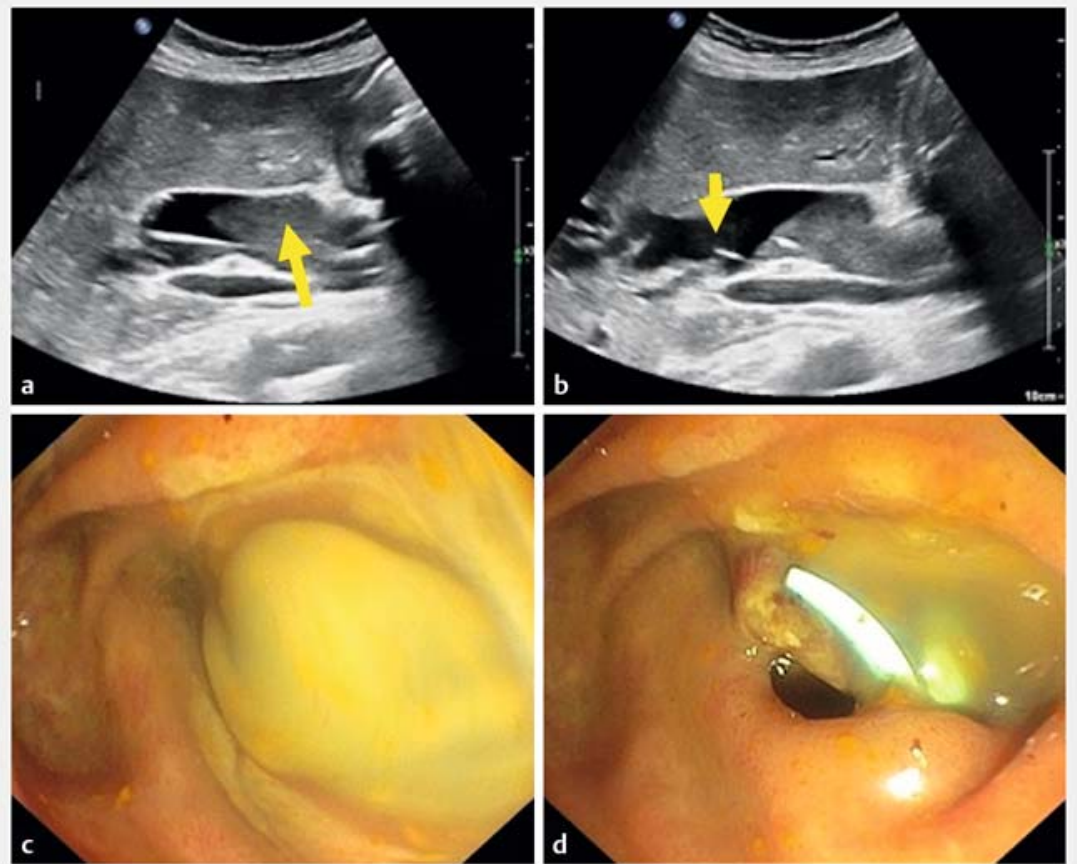

- Fig. 1 Endoscopic retrograde transabdominal ultrasound-guided bile duct drainage. a Transabdominal ultrasound showing a dilated common bile duct with pus and sludge (yellow arrow). b Balloon (yellow arrow) inside the massively dilated common bile duct. c Massive amounts of pus being removed from the bile duct. $\mathbf{d}$ Plastic stent in situ.

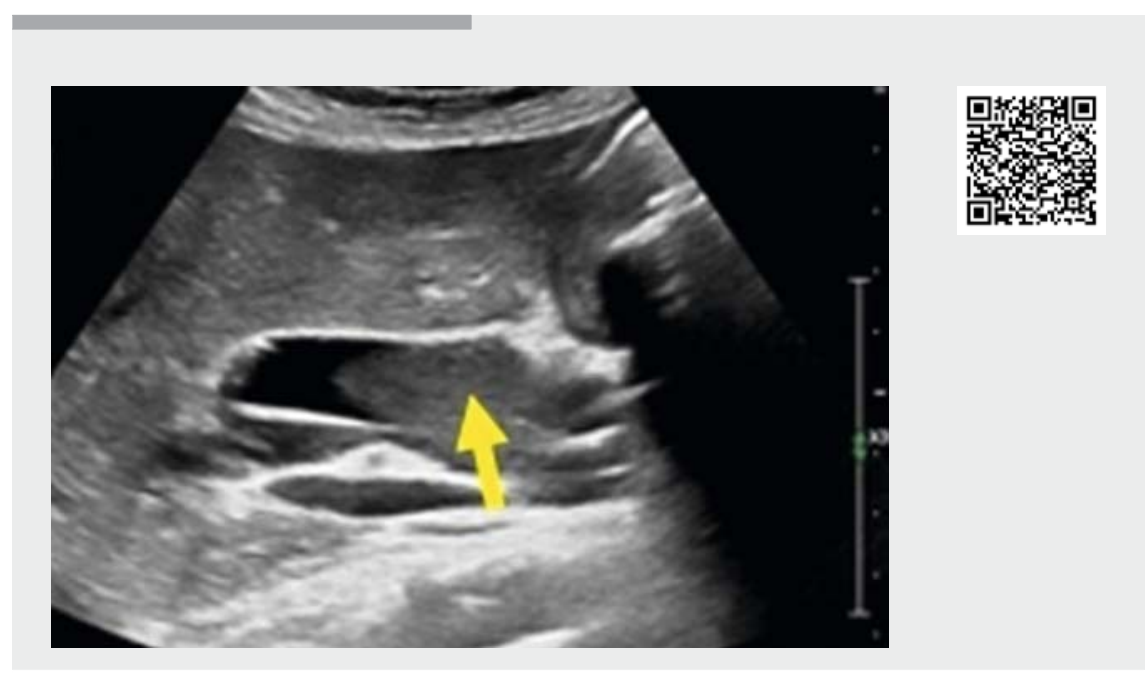

$\checkmark$ Video 1 Endoscopic retrograde transabdominal ultrasound-guided bile duct drainage. 
undergo ERCP using transabdominal ultrasound and/or percutaneous drainage. Therefore, we proceeded to perform transabdominal ultrasound-guided endoscopic drainage of the bile duct (ERUG).

The patient was placed in the left-semilateral position, supporting her right back with a cushion. The abdominal ultrasound was performed by an expert physician sonographer, who performed the procedure on the patient's right side using a C5-1-ultrasound head (EPIQ Elite; Philips, Bothell, WA, USA). Endoscopy was performed with a standard duodenoscope (TJF-Q180V; Olympus, Hamburg, Germany) ( $\triangleright$ Video 1$)$. The papilla was massively swollen, but cannulation was easily achieved with a Clevercut sphincterotome (Olympus) and a 0.025-inch Visiglide wire (Olympus). Drainage of pus was achieved. In addition, sludge and pus were removed using a balloon $(\nabla \mathbf{V i}$ deo 1). A plastic stent (Amsterdam type, $7 \mathrm{~cm}, 10 \mathrm{Fr}$; Cook, Limerick, Ireland) was inserted into the bile duct to guarantee the outflow of pus. The patient recovered rapidly and was discharged home 72 hours later.

To the best of our knowledge, this is the first video report of ERUG. We present the detailed steps of a novel, transabdominal-ultrasound, radiation-free technique to perform endoscopic bile duct drainage. Avoidance of contrast injection also decreases the chances of worsening a septic cholangitis, as contrast is known to increase the bile duct pressure and worsen cholangitis [2]. This technique may be especially helpful in situations when radiation poses a risk, such as childhood and pregnancy. In addition, a C-arm may not always be available such as during a pandemic or in underserved areas of the world, thus allowing this technique to increase the armamentarium of the therapeutic endoscopist.

\section{Endoscopy_UCTN_Code_TTT_1AR_2AK}

\section{Competing interests}

Philips has loaned ultrasound equipments and has made available program booklets for the 4-day annual sonography courses of Dr. Steffen Rickes and Dr. Peter Rauh.

\section{The authors}

Klaus Mönkemüller ${ }^{1,2}$, Peter Rauh', Steffen Rickes ${ }^{1}$

1 Department of Internal Medicine, AMEOS Clinic, Halberstadt, Germany

2 University of Belgrade, Belgrade, Serbia

Corresponding author

\section{Steffen Rickes, MD, PhD}

AMEOS Klinikum Halberstadt,

Akademisches Lehrkrankenhaus,

Gleimstraße 5, D - 38820 Halberstadt, Germany

Fax: +49-3941-645360

sric.med@halberstadt.ameos.de

\section{References}

[1] Kiriyama S, Kozaka K, Takada T et al. Tokyo Guidelines 2018: diagnostic criteria and severity grading of acute cholangitis (with videos). J Hepatobiliary Pancreat Sci 2018; 25: $17-30$

[2] Sud R, Puri R, Hussain S et al. Air cholangiogram: a new technique for biliary imaging during ERCP. Gastrointest Endosc 2010; 72 : 204-208

Bibliography

Endoscopy 2020; 52: 925-926

DOI 10.1055/a-1202-9891

ISSN 0013-726X

published online 13.7.2020

(c) 2020. Thieme. All rights reserved.

(c) Georg Thieme Verlag KG Stuttgart · New York

\section{ENDOSCOPY E-VIDEOS}

https:/|eref.thieme.de/e-videos

口回 Endoscopy E-Videos is a free

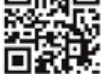
access online section, reporting on interesting cases and new

techniques in gastroenterological endoscopy. All papers include a high quality video and all contributions are freely accessible online.

This section has its own submission website at https://mc.manuscriptcentral.com/e-videos 